\title{
A construção colaborativa do ato de ensinar: impactos do subprojeto A World of Englishes em contexto de formação inicial
}

\section{The Collaborative Construction of the Act of Teaching: Impacts of the A World of Englishes Project in the Context of Initial Training}

\author{
Alessandra da Silva Quadros-Zamboni* \\ *Universidade Estadual do Paraná (Unespar), Paranaguá, Paraná / Brasil \\ asqz@uol.com.br \\ http:/ / orcid.org/0000-0003-0937-9486
}

\begin{abstract}
RESUMO: Este artigo objetiva analisar quatro aspectos referentes à implementação de um subprojeto de formação inicial de professores de língua inglesa: opção pelo magistério e pelo subprojeto; impressões sobre o subprojeto; impactos do subprojeto sobre os alunos-professores em formação; e quais desafios se apresentam em termos de formação acadêmica e profissional. O subprojeto fundamentou-se nas concepções teóricas de língua como discurso (BAKHTIN, 2010; JORDÃO; FOGAÇA, 2007), letramento crítico (CERVETTI; PARDALES; DAMICO, 2001; MUSPRATT; LUKE; FREEBODY, 1997) e inglês como língua franca (DEWEY, 2012; EL KADRI, 2010; SEIDLHOFER, 2001). A análise apoiou-se nos dados gerados por questionários respondidos pelos alunos-professores participantes do subprojeto. Os resultados apontam para uma visão mais amadurecida sobre a profissão e a atuação docente, aumento da autoestima dos alunos-professores e desenvolvimento de estratégias para a superação das dificuldades individuais e coletivas.
\end{abstract}

PALAVRAS-CHAVE: formação inicial; ensino de língua inglesa; letramento crítico; inglês como língua franca; Pibid.

ABSTRACT: This article aims to analyze four aspects related to the implementation of an initial English teacher training project: option for teaching and the project; impressions on the project; impacts of the project on future teachers in training; and what challenges are presented in terms of academic and professional education. The project was based on theoretical conceptions of language as discourse (BAKHTIN, 2010; JORDÃO; FOGAÇA, 2007), critical literacy (CERVETTI; PARDALES; DAMICO, 2001; MUSPRATT; 
LUKE; FREEBODY, 1997) and English as a lingua franca (DEWEY, 2012; EL KADRI, 2010; SEIDLHOFER, 2001). The analysis was based on data generated from questionnaires answered by the furure teachers who participate in the project. The results point to a mature vision about the profession and the teaching performance, increase in the self-esteem of the future teachers and development of strategies to overcome individual and collective difficulties.

KEYWORDS: initial education; English teaching; critical literacy; English as a lingua franca; Pibid.

\section{Introdução}

O presente artigo busca compartilhar experiências do subprojeto Programa Institucional de Bolsas de Iniciação à Docência (Pibid-Inglês) intitulado A World of Englishes, sob a coordenação desta autora, durante o período de março de 2014 a dezembro de 2016. Aspectos recorrentes na formação inicial são objetos de estudo por parte de diversos pesquisadores da área de linguística aplicada (CRISTÓVÃO, 2010; GIMENEZ, 2004; GIMENEZ; RAMOS, 2014; JORDÃO, 2006, 2013; QUADROSZAMBONI, 2015, 2016), cujas pesquisas abordam tanto questões de como se processa essa formação quanto quais são os conhecimentos, saberes ou competências necessários para o ensino de língua (BARCELOS, 2004). Do mesmo modo, questões que envolvem a formação continuada são também alvo de investigação na área (HALU, 2010; JAMOUSSI, 2013; ZAMBONI; JAMOUSSI, 2010).

Nesse contexto de formação inicial e continuada, situa-se o referido subprojeto, através do qual foram desenvolvidas atividades educacionais de ensino e extensionistas de formação inicial e continuada, por meio da inserção dos alunos-professores do curso de Letras Português-Inglês nos contextos educacionais. As ações desenvolvidas envolveram atividades de reflexão teórica e elaboração colaborativa de aulas, metodologias e materiais didáticos para os alunos de três escolas da rede pública estadual do município de Paranaguá, situada no leste litorâneo paranaense. As atividades desenvolvidas no subprojeto foram norteadas por um arcabouço teórico que engloba a perspectiva da língua como discurso (BAKHTIN, 2010; FOUCAULT, 1996, 2005, 2006; JORDÃO, 2006, 2007a; JORDÃO; FOGAÇA, 2007), do letramento crítico (CERVETTI; PARDALES; DAMICO, 2001; MUSPRATT; LUKE; FREEBODY, 1997;) e do ensino de língua inglesa por meio do procedimento Sequência Didática (SCHNEUWLY; DOLZ; 
NOVERRAZ, 2004). Conforme apontam pesquisas que envolvem esse contexto de formação inicial (HIBARINO, 2015; MATEUS; EL KADRI; SILVA, 2013; PASSONI et al., 2013; STUTZ, 2014), o Pibid tem gerado impactos positivos nos espaços em que atua, em termos de formação inicial e continuada, com relevantes resultados na Educação Básica.

Os impactos do subprojeto sobre os alunos-professores são objetos de reflexão neste artigo, que está dividido em quatro seções: primeiramente, apresento algumas considerações sobre língua, letramento crítico e ensino de língua inglesa; na segunda seção, descrevo a metodologia utilizada para a geração dos dados; a terceira seção apresenta a análise dos dados produzidos; por fim, as considerações finais trazem as reflexões gerais sobre a análise dos dados.

\section{Língua, letramento crítico, língua franca e ensino de língua inglesa}

Nesta seção são apresentados os conceitos de língua e de seu ensino que norteiam o subprojeto. A concepção de língua adotada neste estudo é a de língua como discurso (BAKHTIN, 2010; FOUCAULT, 1996, 2005, 2006; JORDÃO, 2006, 2007a, 2007b, 2013; JORDÃO; FOGAÇA, 2007). Nesta perspectiva, a língua e seu ensino são concebidos não a partir de sua estrutura, mas como um contexto de construção e negociação de sentidos e de estabelecimento de procedimentos interpretativos que identifiquem as relações de poder que se estabelecem nos discursos, sem se perder de vista o caráter indissociável entre sujeito e realidade - e suas leituras subjetivas. Conforme Jordão (2006, p. 7),

Conceber a língua como discurso é percebê-la como ideológica, perpassada por relações de poder que ela mesma constrói; é perceber as marcas de determinações culturais nos textos que produzimos; é perceber os gêneros discursivos como mecanismos de estabelecimento de sentidos possíveis.

Desse modo, a língua e, consequentemente, o seu ensino não se apresentam dissociados de seus falantes e de seus valores sociais, culturais e ideológicos. Por outro lado, o letramento crítico (CERVET'TI; PARDALES; DAMICO, 2001; MUSPRATT; LUKE; FREEBODY, 1997) está imerso nas concepções advindas do pós-estruturalismo e da percepção de discurso foucaultiana (FOUCAULT, 1996, 2005, 2006). A noção do quanto as 
relações de poder estão imbricadas nas relações sociais e, por conseguinte, na língua e nos discursos informa um outro olhar para o ensino de línguas. De acordo com Jordão e Fogaça (2007, p. 88), “o poder (e os resultantes conflitos), as formas como o poder opera e as possibilidades de subvertêlo, devem ser uma preocupação fundamental para todos que desejam compreender, ensinar e aprender línguas estrangeiras". Esse outro olhar se percebe inserido nas relações de poder que se estabelecem nos mais diversos contextos e é, portanto, isento de neutralidade, uma vez que se encontra condicionado aos procedimentos interpretativos das comunidades às quais pertence (JORDÃO; FOGAÇA, 2007, p. 90).

O título do subprojeto, A World of Englishes, revela a perspectiva de ensino de língua inglesa adotada no subprojeto, a de Inglês como Língua Franca (ILF), perspectiva essa que traz relevantes implicações ao ensino de língua inglesa (EL KADRI, 2010). Na perspectiva do ILF, o mito do falante nativo (OLIVEIRA, 2014) é questionado, pois seu poder central sobre a língua é deslocado e distribuído entre os falantes desta. Desse modo, a hegemonia das normas dos falantes nativos cede lugar à legitimidade da variedade utilizada por diferentes comunidades de fala (BORDINI; GIMENEZ, 2014). Como decorrência, esse entendimento traz implicações para o ensino de língua inglesa, uma vez que o deslocamento de posse e poder linguísticos do falante nativo para os seus diversos falantes pressupõe uma aceitação de normas linguísticas mais flexíveis. Questões até então consideradas intocáveis, como a "pronúncia correta", o conceito de erro e as diferenças entre o inglês britânico e o estadunidense (considerados até recentemente pelo senso comum como os únicos ingleses corretos e aceitáveis) deixam de ser relevantes na perspectiva do ensino de ILF. Em seu lugar, surge o ensino de variedades de inglês distintas entre si e de diferentes culturas originadas de diversos países, ou seja, diferentes olhares sobre o mundo.

Derrubar esse mito, contudo, não é tarefa fácil, já que ele é fortemente reforçado pela macroengrenagem político-econômica dominante, com forte sustentação da indústria editorial. Conforme esclarece Siqueira (2011, p. 104),

A indústria editorial elege o modelo do falante nativo, já que, entre outras vantagens e facilidades, materiais didáticos podem ser comercializados em escala global, gerando ganhos financeiros estratosféricos e mantendo certos privilégios históricos praticamente intactos. 
Todavia, as atuais configurações mundiais demandam a presença de cidadãos globais, sujeitos com perspectivas mais amplas de mundo, abertos às diferentes configurações sociais, culturais, linguísticas etc. Nesse contexto, não mais há espaço para a concepção de que somente uma variedade da língua mais usada para a comunicação mundial é a correta.

\section{Procedimentos metodológicos}

Esta pesquisa constitui-se como qualitativa, interpretativa, de cunho etnográfico (WIELEWICKI, 2001) e está fundamentada sobre os pressupostos teórico-metodológicos dos paradigmas pós-estruturalistas, cuja ênfase se estabelece sobre o texto e o discurso como elementos constitutivos da realidade (SILVA, 1996). Em vista disso, a seguir será apresentado o contexto em que se originou esta pesquisa, seus participantes, os instrumentos de geração de dados e o percurso percorrido para a análise.

\subsection{Contextualização}

O subprojeto Pibid-Inglês A World of Englishes foi desenvolvido no campus litorâneo de uma universidade pública paranaense, estando vinculado ao seu projeto institucional, e possuía como objetivo geral "contribuir para com a formação docente dos alunos do curso de Letras Português-Inglês por meio da interação com os campos de atuação profissional, em um caminhar conjunto entre formação teórica e prática" (QUADROS-ZAMBONI, 2014, p. 2), tendo sido desenvolvido inicialmente em parceria com três escolas estaduais de Educação Básica ${ }^{1}$ localizadas no município de Paranaguá. O subprojeto possuía como objetivos específicos:

1 Contemplar as necessidades formativas: a) da formação inicial, por meio de um processo de ação reflexivo-formativa que alie os conhecimentos teóricos aos contextos de atuação profissional do aluno-professor; b) da formação continuada, aliando a pesquisa e a reflexão a respeito das necessidades metodológicas do professor da Educação Básica; e c) do aluno da escola pública, por meio do desenvolvimento de atividades que lhe possibilitem um aprendizado efetivo da língua inglesa;

\footnotetext{
${ }^{1}$ Após um período de turbulência enfrentado nacionalmente pelo programa a partir de 2015, houve redução dos alunos-professores bolsistas para 12 (mais tarde, aumentou para 13) e, consequentemente, a perda de um supervisor e de sua respectiva escola.
} 
2 Estabelecer ações elaboradas de forma colaborativa entre os alunosprofessores e os professores da Educação Básica;

3 Elaborar colaborativamente entre alunos-professores, professores e pesquisadores material didático para utilização nas aulas de língua inglesa na Educação Básica.

O subprojeto atuou em três estabelecimentos de Educação Básica e era composto pela professora coordenadora de área e por três professores supervisores, cada um responsável pelo acompanhamento de cinco alunos participantes do subprojeto, perfazendo um total de 15 alunos-professores. Conforme veremos em detalhes a seguir, durante o período em que foi desenvolvido, o subprojeto atuava simultaneamente por meio das seguintes atividades: a) reuniões semanais do grupo de estudos; e b) atividades desenvolvidas nas escolas.

\section{- Reuniões semanais do grupo de estudos:}

$\mathrm{Na}$ primeira fase do subprojeto, as reuniões semanais foram desenvolvidas em duas etapas: na primeira, que durou aproximadamente um semestre, ocorreram leituras e discussões fundamentadas no referencial teórico, composto de documentos oficiais que orientam o ensino de língua inglesa (Parâmetros Curriculares Nacionais, Orientações Curriculares, Diretrizes Curriculares do Estado do Paraná, dentre outros documentos oficiais que orientam o ensino de línguas) e que proporcionem reflexão sobre o contexto educacional e o seu ensino (CRISTÓVÃO, 2010; GIMENEZ, 2004; JORDÃO, 2006, 2007a, 2007b). Na segunda etapa das reuniões semanais do grupo, no semestre seguinte, aconteceram proposições e discussões coletivas de atividades voltadas ao ensino de língua inglesa. Foi também solicitado aos alunos-professores que, a cada encontro, sugerissem um site que contivesse sugestões de atividades voltadas para o ensino de língua, seguido da proposição e discussão de uma atividade específica.

Como é de amplo conhecimento, as aulas de língua inglesa no ensino regular historicamente privilegiam o desenvolvimento das habilidades de leitura e escrita, deixando a compreensão oral e a prática da oralidade para o segundo plano. Essa postura evidencia-se ainda mais em contextos de ensino de escolas públicas, sendo um dos principais motivos para que isso ocorra a presença de dificuldades relacionadas à ausência ou precariedade de recursos estruturais e materiais, além da insegurança do próprio professor 
com relação ao seu conhecimento linguístico em inglês. Em vista disso, foi acordado inicialmente entre os participantes do subprojeto que as proposições deveriam centrar-se, nos primeiros meses, em atividades voltadas para a oralidade (listening e speaking), sendo no segundo semestre voltadas para a leitura e produção escrita.

A escolha dessa ordem das atividades foi proposital, uma vez que buscávamos subverter a ordem com que a língua inglesa é aprendida e ensinada na escola pública, ou seja, privilegiando o texto escrito e não dedicando muita ênfase às atividades que envolvam compreensão e produção oral. Desse modo, buscávamos também equilibrar o desenvolvimento das atividades desenvolvidas em sala de aula, por meio do trabalho tanto com textos orais quanto escritos. Essa escolha deveu-se também a uma tentativa de atender à necessidade de um maior desenvolvimento das habilidades orais em língua inglesa dos estudantes das escolas parceiras do subprojeto, aliandose à nossa concepção de língua como discurso, como veículo de interação social, de leitura e de posicionamento diante do mundo (BAKHTIN, 2010, 2011; FREIRE, 2011; JORDÃO, 2013; VYGOTSKY, 2007, 2008).

Durante os encontros do grupo de estudos, as atividades desenvolvidas nas escolas, trocas de experiências, dúvidas e sugestões eram trazidas para o debate e analisadas coletivamente pelos alunos-professores e coordenadora.

\section{- Atuação nas escolas:}

No momento da atuação nas escolas, os alunos desenvolveram suas atividades sob a supervisão de um professor. A primeira escola (doravante E1) é uma escola tradicional do município e localiza-se na região central de Paranaguá. Oferece turmas no $3^{\circ}$ e $4^{\circ}$ ciclos do ensino fundamental e ensino médio. Possuía no período em que o subprojeto esteve sob minha responsabilidade um total de 1654 alunos. A segunda escola (doravante E2) localiza-se em um bairro residencial. Oferece, igualmente, turmas no $3^{\circ}$ e $4^{\circ}$ ciclos do ensino fundamental e ensino médio, e contava com 1944 alunos. A terceira escola (doravante E3), também localizada em um bairro residencial, oferta ensino de Educação entre Jovens e Adultos (EJA) por disciplina nos ensinos fundamental e médio, e possuía no período 816 alunos. ${ }^{2} \mathrm{O}$ contexto de atuação do subprojeto encontra-se sintetizado no Quadro 1.

\footnotetext{
${ }^{2}$ Os dados obtidos são referentes ao ano letivo de 2014 e foram extraídos do sítio da Secretaria Estadual de Educação, disponíveis em: http://www4.pr.gov.br/escolas/ dadosEscola.jsp. Acesso em: 25 maio 2014.
} 
QUADRO 1 - Contexto de atuação do subprojeto

\begin{tabular}{|l|c|c|c|}
\hline \multicolumn{1}{|c|}{ Participantes } & Escola E1 & Escola E2 & Escola E3 \\
\hline Alunos-professores (bolsistas de iniciação à docência) & 5 & 5 & 5 \\
\hline Supervisores & 1 & 1 & 1 \\
\hline Turmas envolvidas & 3 & 5 & 5 \\
\hline
\end{tabular}

As ações desenvolvidas ocorreram da seguinte forma:
a) Geração de dados sobre o contexto escolar;
b) Observações das aulas dos professores supervisores;
c) Discussões teóricas e problematizações compartilhadas no grupo de estudos;
d) Planejamento colaborativo das aulas;
e) Concepção e produção de material didático;
f) Aplicação conjunta de unidade didática.

Cada escola recebeu um grupo de cinco alunos-professores que iniciou a geração de dados sobre o contexto escolar, analisando sua estrutura, recursos disponíveis, acompanhando as aulas e iniciando as reuniões com os professores supervisores. Paralelamente, aconteciam os grupos de estudo, que eram reuniões semanais entre a coordenação do subprojeto e os alunos-professores, momento em que eram debatidos os textos de embasamento teórico e as questões geradas durante a atuação nas escolas, estabelecendo-se um processo de reflexão teórico-prática sobre a prática docente. Infelizmente, não foi possível conciliar a agenda dos professores supervisores à dos encontros semanais, desse modo, as discussões teóricas entre os professores supervisores e os alunos-professores aconteciam nos encontros realizados nas escolas durante a semana, geralmente no horário de hora-atividade dos professores supervisores. Concomitantemente, também aconteciam o planejamento colaborativo das aulas e a produção de material didático, tanto nas escolas junto aos professores supervisores quanto nos encontros semanais do grupo de estudos do subprojeto. Após o planejamento conjunto, elaboração e confecção dos materiais didáticos, a unidade didática era trabalhada nas aulas, nas turmas em que os alunosprofessores atuavam, seguindo-se de reuniões entre os alunos-professores e os professores supervisores para análise das atividades desenvolvidas. Desse 
modo, a dinâmica do processo acontecia em espiral, uma vez que as ações mencionadas eram constantemente retomadas, realçando-se o processo de discussão e planejamento coletivos.

\subsection{Participantes}

O objetivo deste estudo é compreender os impactos gerados pelo subprojeto A World of Englishes sobre os alunos-professores ${ }^{3}$ nele envolvidos. O questionário foi respondido por seis alunos-professores, sendo três do $4^{\circ}$ ano, dois do $3^{\circ}$ e um do $1^{\circ}$ ano do curso de Letras Português-Inglês. Os questionários foram entregues a todos os alunosprofessores que atuavam no subprojeto no momento, contudo somente seis respondentes os retornaram, apesar da anonimidade ser garantida pela ausência de identificação.

\subsection{Instrumentos de geração de dados}

Os dados foram obtidos por meio de um questionário com questões abertas, entregue aos alunos-professores. As questões apresentadas aos alunos-professores estão divididas em três categorias de análise: a) Opção pelo magistério e pelo subprojeto (questões um a três); b) Impressões sobre o subprojeto (questões quatro a seis); e c) Impactos e desafios (questões sete a nove). Para preservar a identidade dos respondentes, os alunos-professores serão identificados pela letra $\mathrm{A}$, seguida dos números de um a seis.

\subsection{Percurso de análise dos dados}

A análise dos dados é interpretativa e percorreu os seguintes procedimentos: estabelecimento de categorias de análise, codificação, tabulação, análise estatística dos dados, avaliação de suas generalizações, inferência de suas relações e interpretação dos dados. A seguir, será apresentada a análise dos temas, conforme os dados coletados junto aos alunos-professores.

\footnotetext{
${ }^{3}$ Devido ao escopo deste artigo, a análise dos dados gerados pelos professores supervisores será abordada em outra oportunidade.
} 


\section{Discussão dos resultados}

Nesta seção serão discutidas as categorias de análise supracitadas, por meio da apresentação de excertos que explicitam os impactos do subprojeto sobre os alunos-professores nessas categorias.

\subsection{Opção pelo magistério e pelo subprojeto}

Conforme os dados apontam, a maioria dos alunos-professores respondentes pretendia previamente atuar como professores, ainda que não necessariamente como professores de língua inglesa. É interessante observar os fatores que os atraíram para o curso de Letras PortuguêsInglês, como o interesse pelo estudo de línguas, a opção inicial por serem professores de português, e não de inglês, e a presença em sua história de vida de professores que lhes despertaram o desejo de atuar no magistério. Um aspecto que também se faz presente é a motivação e o estímulo pela docência provocados pela atuação no subprojeto, conforme se verifica nos excertos a seguir.

[...] Fiz porque me interessava pelo estudo de línguas. Havia considerado ser professor, embora não fosse exatamente meu objetivo (A1).

Ao iniciar o curso na faculdade já havia a pretensão de atuar na área da educação como professora. Quando comecei a participar do projeto A World of Englishes foi possível perceber como é a atuação de um professor, das dificuldades encontradas, no entanto, não perdi a vontade de ser professora (A2).

Sim, mas eu pensava em ser professor de português e deixar inglês em segundo plano, ou talvez um curso de línguas no currículo (A4).

Sim, eu já pretendia ser professor e o Pibid fez com que minha vontade aumentasse ainda mais (A5).

Sim, eu já tinha interesse por essa profissão desde garoto, sempre tive bons professores que me estimulavam a seguir a carreira que eu gosto (A6).

O interesse pelo subprojeto de inglês revelou aspectos como a busca de um complemento para a formação docente, a possibilidade de dedicação integral à formação oportunizada pela bolsa de estudos e a busca de experiência. Um outro aspecto que os alunos-professores consideraram relevante foi a sensação de maior segurança ofertada pela atuação em grupo e a oportunidade de negociação coletiva das práticas metodológicas. 
Como o curso que escolhi é licenciatura e sairia dele formado como professor, achei que o Pibid poderia contribuir para essa formação (A1).

[Decidi me candidatar ao programa] Para adquirir conhecimento e experiência na atuação de professor. Também com a participação no programa Pibid foi uma maneira de ganhar mais tempo para me dedicar aos estudos sem estar com emprego fixo (A2).

Por querer seguir a carreira e não possuir nenhuma experiência em sala de aula, vi o projeto como um meio de dar esse primeiro passo e ganhar experiência. Algo que também me fez candidatar ao programa foi o fato de termos reuniões e discussões em grupo sobre as práticas em sala de aula, isso me deixou animado para participar, pois senti que seria algo muito construtivo e positivo essa troca de informações (A3).

Eu decidi entrar no programa Pibid porque é uma oportunidade de exercer a função de professor e também de aprender um pouco mais sobre métodos de ensino de língua inglesa (A5).

Eu vi no Pibid uma maneira de estar na pele de um professor na prática, assim quando eu conseguir o diploma já vou estar familiarizado com as atitudes que devo tomar dentro e fora do ambiente escolar (A6).

A terceira questão a respeito da opção pela profissão docente e pelo subprojeto buscava investigar se a participação no Pibid havia alterado a perspectiva do alunos-professores com relação à sua opção pela docência. As respostas assinalaram para uma visão mais segura tanto sobre a profissão quanto sobre a atuação docente, bem como sobre as demandas exigidas pelo ensino público. Verificou-se também um aumento na própria autoestima dos respondentes, ao se sentirem um elemento importante para a formação de seus futuros alunos.

[...] Me sinto muito mais preparado e sinto que entendo mais sobre ensino e aprendizagem do que quando antes de entrar para o projeto (A1).

[Minha opinião sobre o exercício do magistério] Não permanece a mesma, não pelo fato de não querer atuar mais como professor, mas por ter mudado minha visão de o que é ser professor e como é ser professor em uma escola pública (A3).

Sofreu alterações na maneira com que eu vejo o ensino de língua inglesa, pois me vejo como parte de algo maior, que é o ensino de língua estrangeira no país (A4). 


\subsection{Impressões sobre o subprojeto}

Como é possível observar nos depoimentos abaixo apresentados, os aspectos positivos apontados pelos respondentes envolvem questões diversas, que enfatizam os benefícios do formato colaborativo das atividades, como a possibilidade de compartilhar conhecimentos, experiências e informações, o apoio mútuo encontrado no coletivo, o aprofundamento dos conhecimentos e práticas metodológicas por meio das discussões nos encontros do grupo de estudos e a união do grupo.

Um dos desafios da formação docente inicial é a articulação entre teoria e prática sem que esses elementos sejam concebidos ou tratados de modo dicotomizado ou antagônico (ALMEIDA FILHO, 2004; COCHRANSMITH; LYTLE, 1999; HALU, 2010; QUADROS-ZAMBONI, 2015). Essa questão é abordada pelos respondentes, que apontam como positiva a possibilidade de relacionar os conhecimentos acadêmicos às práticas docentes de sala de aula. Conforme os respondentes, a participação no programa Pibid lhes possibilita uma formação docente mais sólida, além da aquisição de experiência profissional e da construção de conhecimento por meio da prática e da reflexão, momento em que tanto as trocas quanto os conflitos são importantes para a formação docente.

Também foi mencionada como positiva a possibilidade de participação dos estudantes do $1^{\circ}$ ano da graduação no subprojeto. Para os respondentes, essa possibilidade, além de oportunizar a experiência docente a partir do início do curso também valoriza os saberes e as capacidades do aluno calouro. Isso contribui para com seu sentimento de valorização tanto acadêmica quanto profissional, como é possível se perceber nos excertos a seguir.

O fato de podermos compartilhar e discutir sobre nossas experiências nas reuniões e também de encontrar suporte para enfrentar dificuldades encontradas a partir dessa troca de experiências; além de "complementar" o curso no sentido de que, pelo menos para mim, às vezes é difícil de estabelecer relações entre o que nós aprendemos no curso e o que teremos que fazer em sala de aula (A1).

$\mathrm{O}$ fato de adquirir experiência porque ao atuarmos como professor saberemos como trabalhar, como, o porquê e o que ensinar aos alunos, além disso adquirimos conhecimento (A2). 
O apoio que temos tanto dos colegas do projeto em sala de aula, quanto do professor supervisor. Tanto as trocas de informações quanto os conflitos de informações nos preparam melhor para o futuro na área (A3).

Considero positivo o fato de o projeto colocar alunos de $1^{\circ}$ ano de formação em licenciatura no contexto escolar, confiar na capacidade desses permitindo uma experiência para o futuro (A4).

Um dos fatores mais positivos que considero no projeto são as discussões nas reuniões a respeito das metodologias do ensino de língua inglesa e o compartilhamento das experiências dos outros parceiros de projeto nas escolas que cada um atua (A5).

A união do grupo e a troca de conhecimento que um passa para o outro (A6).

Não foram enfatizados aspectos negativos do subprojeto pelos respondentes, ou por estarem satisfeitos ou talvez por eles não se sentirem confortáveis em apontar fragilidades do programa. Contudo, o aspecto apontado como deficitário foi a ausência de maior autonomia nas decisões e práticas docentes em sala de aula, em virtude de uma atuação considerada castradora de certo modo, por parte dos professores supervisores. Obviamente, os alunos buscavam maior autonomia em sala de aula, e essa busca entrava em conflito com as responsabilidades e atribuições dos professores supervisores, que não se sentiam muito confortáveis com a implementação de mudanças mais extremas em suas aulas. Desse modo, é possível perceber o desejo de uma participação cada vez mais crescente e ativa em sala de aula por parte do aluno-professor, bem como de seu crescimento em termos de maturidade profissional, a ponto de buscar ampliar o seu espaço, independentemente de a atuação do professor supervisor ter sido corretamente avaliada pelo respondente ou não:

Minhas considerações negativas são ligadas ao ambiente de atuação. Uma delas é a grande influência do professor supervisor no trabalho dos alunos, com influência quero dizer muito do professor supervisor no trabalho na escola e alunos/aprendizes apenas seguindo regras, acredito que isso penaliza a produção dos alunos aprendizes (A4).

Com relação às dificuldades enfrentadas, os respondentes elencaram as seguintes: 
- Relacionar a prática pedagógica ao referencial teórico abordado no grupo de estudos, evidenciado pela busca por inovação na prática docente, por meio da substituição de um ensino superficial e sistêmico da língua por uma abordagem da língua como discurso, como um lócus de produção de sentidos;

- Dificuldades relacionadas às questões metodológicas, tanto com relação à transposição didática quanto ao emprego de estratégias eficazes de motivação dos alunos em sala de aula, além de aspectos relacionados à insegurança provocada pela inexperiência;

- Ausência de proficiência linguística em língua inglesa.

Contudo, alguns respondentes relataram estratégias de superação das dificuldades, tanto de forma individual quanto coletiva, como o estudo individual de conteúdos ainda não dominados, além da superação dos obstáculos através da prática em sala de aula, do arcabouço teórico e das reflexões suscitadas no grupo de estudos.

Outro aspecto presente nos relatos foi a consciência por parte dos alunos-professores de que ser professor não significa saber tudo, mas que é preciso planejar a aula com antecedência, buscando o domínio do assunto a ser ensinado. Os exemplos a seguir revelam esses aspectos.

Alguns textos são complicados para entender, questões relacionadas à disponibilidade de tempo, frustrações quando algo não sai como esperado, nem sempre sei o que fazer quando diante de alguma dificuldade, não conseguir trabalhar de modo a suprir a necessidade de todos/maioria dos alunos, não saber exatamente como coletar e analisar dados, etc. (A1)

Como agir com os alunos no momento em que entrei em sala de aula, pensar numa maneira em que fosse possível fazer os alunos se interessarem em aprender, numa maneira de chamar a atenção deles para o conteúdo que estava sendo ensinado. Também pensar em atividades que fugissem da estrutura da língua (A2).

No momento, nenhuma. Mas durante a primeira tentativa de produzir uma sequência didática tivemos muita dificuldade, tanto em produzir quanto em aplicar o que planejamos (A3).

Um pouco de dificuldade em falar inglês nas aulas na escola, mas estou driblando essas dificuldades estudando alguns vocabulários de escola, e os assuntos os quais terei que falar sobre antes de aplicar aulas (A4). 
A maior dificuldade enfrentada por mim no projeto foi a falta de didática para atuar como professor pela primeira vez em sala de aula. Porém, com o decorrer das reuniões e das leituras propostas, consegui adquirir mais experiências para atuar e hoje me sinto melhor preparado para exercer a função (A5).

Os excertos acima evidenciam a presença de um conhecimento profissional amadurecido, através do qual os alunos-professores se revelam conhecedores dos papéis, dificuldades e estratégias da atuação docente.

\subsection{Impactos e desafios}

Conforme já demonstrado em estudos anteriores (FETZNER; SOUZA, 2012; GOMES et al., 2015; JORDÃO, 2013; MAFRA; CORRÊA, 2015; MATEUS; EL-KADRI; SILVA, 2013; OLIVEIRA, 2017), o Pibid produz significativos impactos sobre os seus atores, tanto em termos de formação inicial quanto continuada, inclusive sobre os sujeitos que o coordenam. Em vista disso, buscou-se gerar dados sobre de que maneira os alunos-professores se sentem impactados pelo programa, bem como quais desafios se fazem presentes em termos de formação acadêmica e profissional.

Os impactos do subprojeto apontados pelos alunos-professores em sua formação são os seguintes:

- Reflexão referente às práticas didático-metodológicas e sobre a própria profissão;

- Suporte proporcionado pelo processo colaborativo;

- Rompimento com práticas metodológicas ineficazes com as quais o respondente teve contato e que até então lhe serviram de modelo;

- Amadurecimento acadêmico e profissional e conquista de maior segurança profissional, adquiridos por meio da obtenção de conhecimento teórico e atuação docente;

- Consciência da disparidade entre diferentes instâncias de ensino, especialmente a discrepância entre as redes pública e particular de ensino. 
Os excertos a seguir ilustram esse tema:

[...] O fato de me fazer pensar sobre o ensino da língua inglesa e me oferecer certo "suporte" (p. ex. com as trocas de experiências, discussões teóricas, etc.), pois sem isso eu provavelmente iria simplesmente reproduzir os métodos de ensino com os quais tive contato enquanto estudante, sem pensar, por exemplo, em estratégias diferentes ou na efetividade delas (A1).

Estou adquirindo experiência e conhecimento. Experiência para atuar na sala de aula e conhecimento para ensinar, tendo clareza naquilo que farei (A2).

Está me fazendo refletir sobre a profissão em si e metodologias de ensino, principalmente por eu estar vivenciando duas realidades opostas no momento: professor de inglês em escola pública e professor de inglês em curso particular de línguas (A3).

Acredito que o maior impacto foi contribuir para a minha nova visão do ensino de línguas, o segundo impacto é a grande contribuição para a minha formação docente (A4).

O Pibid está me mostrando as dificuldades que enfrentarei na sala de aula após a minha graduação e isso faz com que eu esteja preparado quando chegar lá (A5).

Ele está me proporcionando muito conhecimento, e me preparando para o momento em que eu vou estar em sala (A6).

Uma das responsabilidades do subprojeto diz respeito aos componentes teóricos elencados para as discussões do grupo de estudos. Em uma perspectiva teórica de concepção de língua como discurso, letramento crítico e inglês como língua franca, a escolha dos componentes teóricos trabalhados no subprojeto visou abordar esses elementos, acrescidos de leitura de embasamento necessário para a formação do professor de inglês, como os Parâmetros Curriculares Nacionais - Língua Estrangeira Moderna, as Orientações Curriculares para o Ensino Médio e as Diretrizes Curriculares do Estado do Paraná - Língua Estrangeira Moderna (PARANÁ, 2009), dentre outros documentos oficiais que discutem a docência de língua estrangeira. A leitura desses documentos se pautou por um olhar reflexivo, ou seja, um olhar que buscava o conhecimento desses documentos, mas ao mesmo tempo se constituía analítico e ponderador sobre seus conteúdos. Aliadas a essas leituras oficiais estiveram presentes outras leituras de 
embasamento, como as relacionadas à perspectiva teórica que sustenta o subprojeto e leituras que suscitavam discussões sobre o papel do professor de língua estrangeira, os desafios impostos pelos contextos de escola pública, a metodologia de ensino e a concepção e construção de sequências didáticas (SCHNEUWLY; DOLZ; NOVERRAZ, 2004), dentre outras.

Dito isso, os impactos relacionados à contribuição do referencial teórico abordado pelo subprojeto e às discussões sobre a formação revelamse como sendo:

- Aquisição de conhecimento em diversos aspectos do ensino;

- Percepção de que a atuação docente é profundamente influenciada pelas concepções teóricas subjacentes;

- Autonomia docente;

- Confrontar os próprios saberes e preconcepções;

- Ressignificação sobre o trabalho docente;

- Suporte teórico para a atuação docente;

- Contexto de discussão teórica utilizado como instância de trocas de informações, experiências e negociação de sentidos.

Acredito que me trazem conhecimento e me dão acesso a instrumentos fundamentais para que eu possa ensinar a língua inglesa (saber o que é a língua e como a forma como abordamos afeta o modo como nós a ensinamos; como funciona o processo de aprendizagem dos alunos e qual o papel do professor nesse processo; identificar problemas e dificuldades de aprendizagem e saber como amenizá-los/solucioná-los o que implica ter um conhecimento bastante aprofundado sobre os dois itens anteriores, etc.) (A1).

Este foi um fator que me fez entrar no projeto, por nos fazer pensar em todas as certezas e preconcepções que temos de como atuar em sala e o que é ser um professor. As discussões com certeza têm me ajudado a reformular muitos pensamentos que tinha sobre vários aspectos dessa área de trabalho (A2).

No entendimento teórico de como ocorre o trabalho do professor na escola, o que me deixa preparado para o bom proceder nas aulas (A3).

As leituras e discussões têm contribuído muito na forma que devo atuar na sala de aula, nas questões metodológicas e de como interagir com alunos/turmas (A4). 
Eu tenho aprendido muito com as atividades em grupo, com elas eu consigo compreender como funciona a cabeça de uma criança ou adolescente, e como eu devo proceder para que o aluno aprenda ao máximo com as atividades que estarão sendo trabalhadas em sala (A5).

Com relação aos desafios a serem superados e ao que pode ser acrescentado ou aprimorado no subprojeto, os respondentes apontaram tanto desafios de ordem pessoal quanto referentes ao subprojeto. Os desafios pessoais se referem a superar temores e inseguranças pessoais e à melhoria da fluência linguística. Com relação ao subprojeto, os alunosprofessores revelam a busca de alternativas para o modelo tradicional de ensino, com o desenvolvimento de atividades significativas e prazerosas para os alunos da Educação Básica.

Superar um pouco do medo na questão de atuar na sala de aula o convívio com os alunos, no trato, e em saber exatamente como agir (A2).

Acredito que um melhor domínio da língua inglesa para melhor atuação na sala de aula (A4).

O que poderia ser acrescentado no projeto seria a elaboração de mais atividades lúdicas a serem trabalhadas durante a atuação nas salas de aula (A5).

Em síntese, as respostas fornecidas pelos alunos-professores indicam três aspectos relevantes em sua formação, proporcionados pelo subprojeto: certeza quanto à sua decisão de atuar profissionalmente como professor/a, noção mais clara sobre o conceito de língua e preparação mais efetiva para a docência.

\section{Considerações finais}

Neste artigo foram analisados quatro aspectos referentes à implementação de um subprojeto de formação inicial de professores de língua inglesa: a opção pelo magistério e pelo subprojeto; as impressões sobre o subprojeto; os impactos do subprojeto sobre os alunos-professores em formação; e os desafios enfrentados pelos alunos-professores em termos de formação acadêmica e profissional. Para o desenvolvimento da análise, foram apresentados a concepção teórica que embasa o subprojeto, informações sobre o contexto da pesquisa, a metodologia de geração e 
análise de dados, e a análise dos dados propriamente dita. Os dados gerados por meio da pesquisa revelam importantes aspectos presentes no programa Pibid, dentre eles os impactos sobre os professores em formação e os desafios para a formação docente inicial do professor de língua inglesa.

Com este trabalho, foi possível observar a necessidade de maior aprofundamento teórico-prático relacionado à perspectiva do ensino de inglês como língua franca junto aos alunos-professores, visto que as atividades desenvolvidas nas escolas ainda se constituíram predominantemente centradas nos modelos linguísticos britânico-estadunidenses. Por sua vez, a relutância por parte dos alunos-professores a se desvincularem dos modelos linguísticos hegemônicos aponta para a necessidade de reflexão sobre as relações de poder subjacentes às escolhas desses modelos, bem como a suas implicações no ensino de língua inglesa. Desse modo, a perspectiva do letramento crítico, observada em algumas das respostas, ainda carece de melhor discussão e aprofundamento tanto na formação inicial quanto na continuada, para que possa se refletir na prática docente.

Obviamente, houve adversidades que também impactaram o próprio subprojeto, como a dificuldade em conciliar os horários de reunião do grupo de estudos com os professores supervisores para um maior aprofundamento teórico; contudo, as discussões teóricas estiveram subjacentes aos encontros entre alunos-professores e supervisores, o que de certa forma minimizou a ausência dos professores supervisores em parte dos encontros. Outra dificuldade encontrada na consecução do subprojeto foram as instabilidades causadas tanto pelo clima de constante ameaça de término do programa quanto pela diminuição no número de bolsistas. Um outro ponto foi a resistência por parte dos alunos-professores e professores supervisores em desenvolverem planejamento de aulas com ênfase nas atividades orais, apesar da orientação por parte da coordenação do subprojeto nesse sentido. Isso se deve, possivelmente, à ausência de proficiência linguística de ambos os atores, devido às carências em termos de formação em língua inglesa na Educação Básica - e na própria graduação - dos sujeitos envolvidos. Em decorrência disso, por não ter intimidade com a língua, os alunosprofessores ainda ofertam resistência ao ensino contextualizado e da língua como discurso, ou seja, como prática social dinâmica, que não se limita a uma concepção sistêmica, estrutural e fixa da língua (JORDÃO; FOGAÇA, 2007), o que demonstra que ainda há um longo caminho a percorrer nesse sentido. 
Por outro lado, há inúmeros pontos positivos a serem salientados, como a possibilidade concreta de aliar teoria e prática, trabalhando-as e vivenciando-as de modo integrado. Um outro aspecto proveitoso foi poder proporcionar aos alunos da graduação a experiência da prática docente a partir do início do curso e o suporte mútuo entre os pares, em que os alunos mais experientes - que não são necessariamente os que cursam séries mais adiantadas - dão suporte aos menos experientes. Essa prática oportuniza aos alunos em formação vencer suas próprias inseguranças e lhes garante autonomia didática e metodológica. Some-se a isso um contexto colaborativo e de formação reflexiva (FREIRE, 1996; PIMENTA, 2005; SCHÖN, 1983, 1995), no qual o futuro professor tem a oportunidade de se graduar muito mais preparado para a realidade da sala de aula.

\section{Referências}

ALMEIDA FILHO, J. C. P. O professor de língua(s): profissional, reflexivo e comunicacional. Revista Horizontes de Linguistica Aplicada, Brasília, DF, v. 3, n. 1, p. 7-18, 2004.

BAKHTIN, M. (VOLOCHÍNOV, V. N.). Marxismo e filosofia da linguagem. Tradução de Michel Lahud, Yara Frateschi Vieira. 14. ed. São Paulo: Hucitec, 2010.

BAKHTIN, M. Estética da criação verbal. Tradução de Paulo Bezerra. 6. ed. São Paulo: Martins Fontes, 2011.

BARCELOS, A. M. F. Ser professor de inglês: crenças, expectativas e dificuldades dos alunos de Letras. In: VIEIRA-ABRAÃO, M. H. (org.). Prática de ensino de lingua estrangeira: experiências e reflexões. Campinas: Pontes Editores, 2004. p. 11-29.

BORDINI, M.; GIMENEZ, T. Estudos sobre inglês como língua franca no Brasil (2005-2012): uma metassíntese qualitativa. Signum: Estudos da Linguagem, Londrina, v. 17, p. 10-43, 2014. Doi: https://doi.org/10.5433/2237-4876.2014v17n1p10

CERVETTI, G.; PARDALES, M. J.; DAMICO, J. S. A tale of differences: comparing the traditions, perspectives and educational goals of critical reading and critical literacy. Reading Online, [S. l.], v. 4, n. 9, abr. 2001.

COCHRAN-SMITH, M.; LYTLE, S. Relationship of knowledge and practice: teacher learning in communities. In: IRAN-NEJAD, A.; PEARSON, C. D. (ed.). Review of Research in Education, Washington, DC, v. 24, p. 249-306, 1999. Doi: https://doi.org/10.3102/0091732X024001249 
CRISTÓVÃO, V. L. L. Gêneros textuais e educação inicial do professor de língua inglesa. Linguagem em (Dis)curso, Florianopólis, v. 10, p. 705-734, 2010. Doi: https:/ / doi.org/10.1590/S1518-76322010000300013

DEWEY, M. Towards a post-normative approach: learning the pedagogy of ELF. Journal of English as a Lingua Franca, Bruxelas, v. 1, n. 1, p. 141-170, 2012. Doi: https://doi.org/10.1515/jelf-2012-0007

EL KADRI, M. S. Inglês como Língua Franca: um olhar sobre programas disciplinares de um curso de formação inicial de professores de inglês. Entretextos, Londrina, v. 10, n. 2, p. 64-91, jul./dez. 2010.

FETZNER, A. R.; SOUZA, M. E. V. Concepções de conhecimento escolar: potencialidades do Programa Institucional de Bolsa de Iniciação à Docência. Educação e Pesquisa, São Paulo, v. 38, n. 3, p. 683-694, 2012. Doi: https://doi. org/10.1590/S1517-97022012005000018

FOUCAULT, M. A ordem do discurso. 17. ed. São Paulo: Loyola, 1996.

FOUCAULT, M. Microfísica do poder. 21. ed. Rio de Janeiro: Graal, 2005.

FOUCAULT, M. Poder e saber. In: Ditos e escritos IV : estratégia, poder-saber. Rio de Janeiro: Forense Universitária, 2006. p. 223-240.

FREIRE, P. Pedagogia da autonomia: saberes necessários à prática educativa. 53. ed. São Paulo: Paz e Terra, 1996.

FREIRE, P. A importância do ato de ler. em três artigos que se completam. 51. ed. São Paulo: Cortez, 2011.

GIMENEZ, T. Tornando-se professores de inglês: experiências de formação inicial em um Curso de Letras. In: VIEIRA ABRAHÃO, M. H. (org.). Prática de ensino de lingua estrangeira: experiências e reflexões. Campinas: Pontes Editores, 2004. p. $171-187$.

GIMENEZ, T.; RAMOS, S. G. M. Planejamento e implementação de curso online como atividade de estágio curricular na área de inglês. Ilha do Desterro, Florianopólis, v. 66, p. 101-131, 2014. Doi: https://doi.org/10.5007/2175-8026.2014n66p101

GOMES, B. D. S.; LOPES, F. E. F.; BARRETO, M. D.; DIAS, V. G. O projeto Pibid e a formação docente: a construção identitária do professor de língua inglesa no alto sertão da Paraíba. Revista ao Pé da Letra, Recife, v. 17, n. 1, p. 77-88, 2015.

HALU, R. C. Formação de formadoras de professores de inglês em contexto de formação continuada. 2010. Tese (Doutorado em Letras) - Universidade Federal do Paraná, Curitiba, 2010. 
HIBARINO, D. A. Co-formação, conflitos e negociações no Pibid-Inglês UFPR. Revista X, Curitiba, v. 1, p. 16-31, 2015. Doi: https://doi.org/10.5380/rvx. v1i0.37557

JAMOUSSI, T. A. Formação continuada de professoras de inglês: as manhãs de sábado de um grupo de estudos. 2013. Tese (Doutorado em Estudos Linguísticos) - Universidade Federal do Paraná, Curitiba, 2013.

JORDÃO, C. M. O ensino de línguas estrangeiras: do código ao discurso. In: VAZ BONI, V. (org.). Tendências contemporâneas no ensino de línguas. União da Vitória: Kaygangue, 2006. p. 26-32.

JORDÃO, C. M. As lentes do discurso: letramento e criticidade no mundo digital. Revista Trabalbos em Linguistica Aplicada, Campinas, v. 46, n. 1, p. 19-29, jan./jun. 2007a. Doi: https://doi.org/10.1590/S0103-18132007000100003

JORDÃO, C. M. O que todos sabem... ou não: letramento crítico e questionamento conceitual. Revista CROP, São Paulo, v. 12, p. 21-46, $2007 \mathrm{~b}$.

JORDÃO, C. M. Letramento crítico, inglês como língua internacional e ensino: as marés do Pibid-Inglês na UFPR. In: MATEUS, E.; EL KADRI, M. S.; SILVA, K. A. (org.). Experiências de formação de professores de línguas e o PIBID. Campinas: Pontes Editores, 2013. p. 21-48.

JORDÃO, C. M.; FOGAÇA, F. C. Ensino de inglês, letramento crítico e cidadania: um triângulo amoroso bem-sucedido. Linguas e Letras, Cascavel, v. 8, n. 14, p. 79105, 2007.

MAFRA, G. M.; CORRÊA, S. A. O Pibid como propiciador de capacidades docentes. Revista ao Pé da Letra, Recife, v. 17, n. 1, p. 89-106, 2015.

MATEUS, E.; EL KADRI, M. S.; SILVA, K. A. (org.). Experiências de formação de professores de linguas e o Pibid: contornos, cores e matizes. Campinas: Pontes Editores, 2013.

MUSPRATT, S., LUKE, A.; FREEBODY, P. (ed.). Constructing Critical Literacies. Cresskill: Hampton Press, 1997.

OLIVEIRA, H. F. A bagagem do Pibid para a formação inicial docente e para a construção da identidade profissional. Trabalhos em Linguística Aplicada, Campinas, v. 56, n. 3, p. 913-934, set./dez. 2017. Doi: https://doi.org/10.1590/010318138 647980236661

OLIVEIRA, L. A. Métodos de ensino de inglês: teorias, práticas, ideologias. São Paulo: Parábola, 2014. 
PARANÁ. Secretaria de Estado da Educação. Diretrizes curriculares da Educação Básica - língua estrangeira moderna. Curitiba: Secretaria de Estado da Educação do Paraná. 2009.

PASSONI, T. P. et al. Subprojeto Pibid de língua inglesa da UNEB/campus X: expectativas e possibilidades na formação de professores. In: MATEUS, E. F.; EL KADRI, M. S.; SILVA, K. A. da. Experiências de formação de professores de línguas e o PIBID: contornos, cores e matizes. Campinas: Pontes Editores, 2013. v. 3, p. 131-153.

PIMENTA, S. G. Professor reflexivo: construindo uma crítica. In: PIMENTA, S. G.; GHEDIN, E. (org.). Professor reflexivo no Brasil: gênese e crítica de um conceito. São Paulo: Cortez, 2005. p. 17-52.

QUADROS-ZAMBONI, A. S. O inglês nosso de cada dia: o subprojeto Pibid e a formação docente dos professores de língua inglesa. In: ENCONTRO NACIONAL DAS LICENCIATURAS, 6., 2016, Curitiba. Anais [...]. Curitiba: PUC-PR, 2016. s. p. Disponível em: https://bit.ly/2XiZxLR. Acesso em: 8 set. 2018.

QUADROS-ZAMBONI, A. S. Apendicite formativa nos cursos de Letras: reflexões sobre a formação do professor de inglês. Campinas: Pontes Editores, 2015.

QUADROS-ZAMBONI, A. S. A World of Englishes. Subprojeto Letras-Inglês/ UNESPAR do PIBID/CAPES, 2014.

SCHNEUWLY, B.; DOLZ, J.; NOVERRAZ, M. Sequências didáticas para o oral e a escrita: apresentação de um procedimento. In: SCHNEUWLY, B.; DOLZ, J. Gêneros orais e escritos na escola. Campinas: Mercado de Letras, 2004. p. 81-108.

SCHÖN, D. The Reflective Practioner. London: Basic Books, 1983.

SCHÖN, D. Formar professores como profissionais reflexivos. In: NÓVOA, A. (coord.). Os professores e sua formação. 2. ed. Lisboa: Dom Quixote, 1995. p. 77-92.

SEIDLHOFER, B. Closing a Conceptual Gap: The Case for a Description of English as a Lingua Franca. International Journal of Applied Linguistics, [S. l.], v. 11, n. 2, p. 133-158, 2001. Doi: https://doi.org/10.1111/1473-4192.00011

SIQUEIRA, S. Inglês como Língua Franca: o desafio de ensinar um idioma desterritorializado. In: GIMENEZ, T.; CALVO, L. C. S.; EL KADRI, M. S. Inglês como Lingua Franca: ensino-aprendizagem e formação de professores. Campinas: Pontes, 2011. p. 87-115.

SILVA, T. T. Identidades terminais: as transformações na política da pedagogia e na pedagogia da política. Petrópolis: Vozes, 1996. 
STUTZ, L. Apresentação do Pibid Letras-Inglês. In: STUTZ, L. (org.). Modelos didáticos de gêneros textuais: as construções dos alunos professores do Pibid Letras Inglês. Campinas: Pontes Editores, 2014. p. 17-29.

VYGOTSKY, L. S. A formação social da mente: o desenvolvimento dos processos psicológicos superiores. 2. ed. São Paulo: Martins Fontes, 2007.

VYGOTSKY, L. S. Pensamento e linguagem. 4. ed. São Paulo: Martins Fontes, 2008.

ZAMBONI, A. S. Q.; JAMOUSSI, T. A. Um olhar sobre a formação do professor de língua inglesa: um caminhar constante e ininterrupto da formação inicial à continuada. In: ENCONTRO DO CÍRCULO DE ESTUDOS LINGUÍSTICOS DO SUL, 9., 2010, Palhoça. Anais [...]. Palhoça: Unisul, 2010. p. 1-10. Disponível em: https://bit.ly/2JP1HQb. Acesso em: 15 set. 2018.

WIELEWICKI, V. A pesquisa etnográfica como construção discursiva. Acta Scientiarum, Maringá, v. 23, n. 1, p. 27-32, 2001.

Data de submissão: 7/10/2018. Data de aprovação: 20/5/2019. 